\title{
Involvement of new oxidative stress markers in chronic spontaneous urticaria
}

\author{
Eustachio Nettis ${ }^{1}$, Maria Distaso ${ }^{1}$, Salvatore Saitta ${ }^{2}$, Marco Casciaro $^{2}$, Mariateresa Cristani ${ }^{3}$, Antonina Saija ${ }^{3}$, \\ Angelo Vacca' ${ }^{1}$, Sebastiano Gangemi², Paola L Minciullo ${ }^{2}$ \\ ${ }^{1}$ Section of Allergology and Clinical Immunology, Department of Internal Medicine and Infectious Diseases, Medical School, \\ University of Bari, Bari, Italy \\ ${ }^{2}$ School and Division of Allergy and Clinical Immunology, Department of Clinical and Experimental Medicine, \\ "G. Martino" University Hospital, Messina, Italy \\ ${ }^{3}$ Department Farmaco-Biologico, School of Pharmacy, University of Messina, Messina, Italy
}

Adv Dermatol Allergol 2017; XXXIV (5): 448-452

DOI: https://doi.org/10.5114/ada.2017.71110

\begin{abstract}
Introduction: Oxidative stress is a result of an imbalance between endogenous production of free reactive oxygen species and reduced effectiveness of antioxidant defence mechanisms. Advanced glycation end products (AGEs) and advanced oxidation protein products (AOPPs) are compounds formed by transformation of macromolecules, including proteins which can serve as markers of oxidative stress and inflammation in several diseases.

Aim: To investigate the role of AGEs and AOPPs as new markers of oxidative stress and inflammation in patients with chronic spontaneous urticaria (CSU).

Material and methods: Advanced glycation end products and AOPP levels were determined in the sera of 85 patients with CSU and 64 healthy controls, using spectrofluorimetry and spectrophotometry, respectively.

Results: Advanced oxidation protein products levels in patients were statistically higher than those in controls. These levels were not affected by the presence of positive autologous serum test results or autologous plasma test results. No statistically significant differences were found between AGE levels in patients and controls.

Conclusions: Formation of AGEs and AOPPs may be accelerated in immunological and allergic disorders. Depending on the sites evaluated, the presence or absence of oxidative stress in chronic urticaria is controversial. To our knowledge, this is the first study showing the possible involvement of AOPPs in CSU. The different behaviour observed for these two biomarkers is very likely due to the activation of specific related biochemical pathways associated with the condition under study.
\end{abstract}

Key words: advanced glycation end products, advanced oxidation protein products, allergy, chronic spontaneous urticaria, oxidative stress, skin disease.

\section{Introduction}

Urticaria is a disease characterized by the development of wheals, angioedema, or both [1]. Urticaria still represents a challenge to allergists due to the complexity of etiologic factors. Despite progress made to improve our understanding of urticaria pathogenesis and treatment, many patients continue to experience ongoing symptoms and impaired quality of life [2, 3]. The spectrum of clinical manifestations of different urticaria subtypes is very wide. Classification of chronic urticaria subtypes has been recently revised and includes chronic spontaneous urticaria (CSU) and inducible urticaria. The CSU is characterized by spontaneous appearance of wheals, angioedema, or both $\geq 6$ weeks due to known or unknown causes [1].

Urticaria is a mast-cell-driven disease and mast cells degranulation initiates the inflammatory process. In chronic urticaria there is an activation of basophils or mast cells causing the release of histamine and other mediators. It has been also seen that there is an intradermal infiltration characterized by mast cells, CD4 T lymphocytes, monocytes, neutrophils, eosinophils, and basophils $[4,5]$.

Address for correspondence: Paola L. Minciullo MD, PhD, Unit of Allergy and Clinical Immunology, Department of Clinical and Experimental Medicine, University Hospital of Messina, Via Consolare Valeria, 98125 Messina, Italy, phone: +39 0902217231, fax: +39090 2217231, e-mail: pminciullo@unime.it

Received: 16.02.2016, accepted: 29.06.2016. 
These inflammatory cells, chronically activated, produce large amounts of free oxygen radicals [6].

Oxidative stress is a result of an imbalance between endogenous production of free reactive oxygen species and reduced effectiveness of antioxidant defence mechanisms. This imbalance can worsen inflammation and injury conditions by enhancing pro-inflammatory cytokines release and altering enzymatic function [7].

Advanced glycation end products (AGEs) and advanced oxidation protein products (AOPPs) are compounds formed by transformation of macromolecules, including proteins which can serve as densitometric markers of oxidative stress and inflammation in several diseases and their complications [8, 9].

Modified proteins may be, more efficiently than other biomarkers, employed to monitor disease progression and outcome, since proteins are, in general, key molecules in various structural and functional aspects of living organisms and their activity and function are strictly dependent on the structure, conformation, and folding pattern. Thus, modification of conformation/structure of the polypeptide chain in conditions of oxidative stress/ inflammation can lead to dysfunction/function, loss of proteins, and inhibition of protein degradation (and, consequently, their accumulation) and can have also a wide range of downstream functional consequences, causing subsequent cellular dysfunction, tissue damage, and disease onset/progression. Furthermore, as the techniques used to measure AGEs and AOPPs are simple, fast, and inexpensive, they may be applicable in daily routine laboratory practice for assessing and monitoring oxidative stress in critically ill and several other types of patients. These biomarkers also have further advantages, as well as other modified proteins (e.g., carbonylated and nitrosylated proteins), of relative stability and consequent higher blood concentrations [10].

In the literature, data related to the oxidative stress status in patients with urticaria are controversial [11-19].

\section{Aim}

The aim of this study was to investigate the role of AGEs and AOPPs as new markers of oxidative stress and inflammation in patients affected by CSU.

\section{Material and methods}

\section{Subjects}

The study was conducted on 85 patients with a diagnosis of CSU (54 women and 31 men) ranging in age from 16 to 77 years (mean \pm SD: $42.4 \pm 14.6$ years). All subjects signed informed consent to enrolment in the study. They were asked to complete a questionnaire detailing sex, age at presentation; family history of allergic rhinitis, asthma, atopic eczema and urticaria; any past history of allergic rhinitis, asthma and atopic eczema; any history of reactions to drugs and foods; duration of the illness; duration of wheals; skin areas involved and associated symptoms.

Sixty-four sex- and age-matched healthy donors were recruited as controls. Each subject gave written informed consent to have their data included for analysis.

\section{Tests performed}

At first visit, after a careful history and accurate physical examination, all patients were submitted to allergological, laboratory and instrumental investigations tailored to the individual clinical history and findings in each patient [20]. Tests included urinalysis, routine laboratory evaluation integrated with C3, C4, C1 inhibitor antigenic level, thyroid function test, antithyroid autoantibodies, antinuclear antibodies, rheumatoid factor, serum immunoglobulins, circulating immune complexes, cryoglobulins, stool screening for blood, parasites and yeast, serology for viral, bacterial and parasite antibodies, serum electrophoresis, gastroscopy, biopsy and ELISA for specific anti Helicobacter pylori lgG antibodies, dental series, sinus series and chest X-ray, and sonography of the upper abdomen. No skin biopsy was done.

Skin prick tests were performed with common available foods and inhalants (Stallergenès, Milan, Italy). In some cases, a "prick-prick test" with the fresh raw food was made. Histamine hydrochloride $(10 \mathrm{mg} / \mathrm{ml})$ was used as positive control, and physiological saline as negative control. The prick test was considered positive if the wheal was more than $3 \mathrm{~mm}$ larger than the wheal of the negative control. Measurement of total IgE level was taken by the PRIST (Thermo Fisher Scientific, Milan, Italy) and specific serum IgE by a fluorescence enzyme-linked immunoassay (ImmunoCAP system; Thermo Fisher Scientific, Milan, Italy). Total IgE levels were measured according to the manufacturer's instructions and PRIST was considered positive at titres $>100 \mathrm{kU} / \mathrm{l}$. The threshold of positivity for the CAP was set at $0.10 \mathrm{kU} / \mathrm{l}$. Skin tests were graded according to the system described by Norman [21]. Reactions graded as 2+ or higher were considered positive. Drug-related aetiology was established on the basis of the criteria laid down by the protocols in literature [22]. Briefly, the methods used to evaluate patients with suspected drug-induced urticaria were a detailed history, withdrawal of the suspected drug, and in some cases in vivo and in vitro testing. In order to evaluate the role of foods and additives, double blind placebo-controlled in vivo provocation tests with foods and additives were performed when necessary [23]. The choice of foods and additives selected for the double blind placebo-controlled provocation tests was determined by history, skin test, or RAST test or by the results of an elimination diet: a 21-day diet in which all foods or additives suspected of causing an urticarial reaction were eliminated. Autologous serum skin tests, performed as previously reported [24], were carried out on all subjects with chronic spon- 
taneous urticaria. Physical challenge tests were used to confirm the diagnosis of physical urticaria [25]. All data regarding investigation results, questionnaire data, patient management, and response to treatment have been collected in a database in our unit.

\section{Sera collection}

Following venous blood drawing, sera were allowed to clot at room temperature for $2 \mathrm{~h}$, then were separated by centrifugation at $1200 \times \mathrm{g}$ for 15 min and stored at $-80^{\circ} \mathrm{C}$ until used.

\section{Determination of AGEs and AOPPs}

Determination of AGEs and AOPPs was based on spectrofluorimetric and spectrophotometric methods, respectively, as previously described [26]. For AGE determination, serum was diluted $1: 50$ with phosphate buffered saline (PBS; $\mathrm{pH} 7.4$ ), and fluorescence intensity was recorded at maximum emission ( $440 \mathrm{~nm})$ upon excitation at $350 \mathrm{~nm}$ and expressed in arbitrary units (AU). The serum concentration of AGEs was normalized to the total protein amount determined by the Bradford assay and expressed in AU for protein gram. For AOPP determination, $200 \mu \mathrm{l}$ of serum was diluted $1: 5$ with PBS, $200 \mu \mathrm{l}$ of chloramines T (0-100 mol/l) for calibration and $200 \mu \mathrm{l}$ of PBS as blank were applied on a microtitre plate. Ten $\mu \mathrm{l}$ of $1.16 \mathrm{MKI}$ and $20 \mu \mathrm{l}$ of acetic acid were added, and absorbance at $340 \mathrm{~nm}$ was measured immediately. The serum concentration of AOPPs was normalized to the total protein amount determined by the Bradford assay and expressed as chloramine nmoles for protein $\mathrm{mg}$. Each sample was analysed in triplicate both for AGE and AOPP determination.

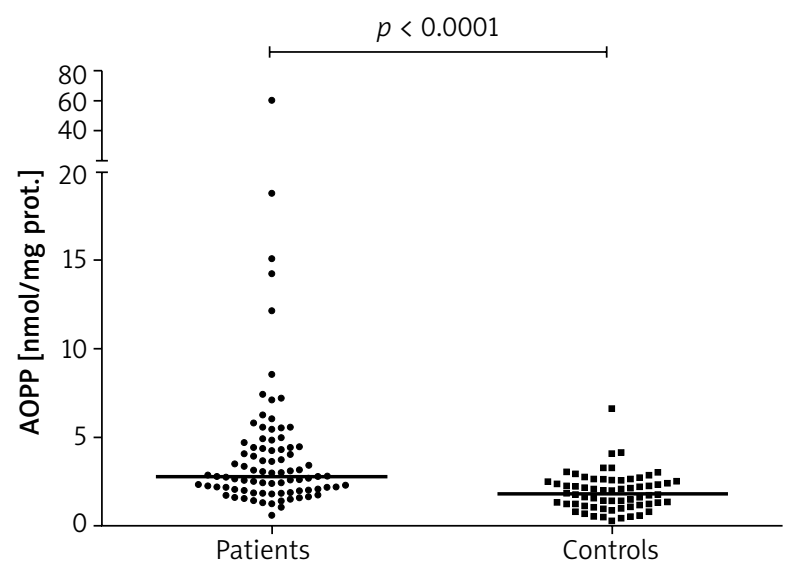

Figure 1. Advanced oxidation protein products (AOPP) concentration in patients and in controls, lines represent means

\section{Statistical analysis}

The statistical analysis was performed with SPSS for Windows (version 17.0). Data were presented as median \pm standard error of mean (SEM). Differences between unpaired groups were analysed by Mann-Whitney test. Correlation between two variables was evaluated with Spearman's rho. Statistical significance was set at $p<0.05$.

\section{Results}

The AOPP levels in patients were statistically higher than those in controls $(2.79 \pm 0.74$ vs. $1.82 \pm 0.13 \mathrm{AU} / \mathrm{g}$ prot.; $p<0.0001$ ) (Figure 1), while there was no statistically significant difference in AGE levels between patients and controls (411.38 \pm 203.86 vs. $416.66 \pm 45.74 \mathrm{nmol} / \mathrm{mg}$ prot.; $p>0.05$ ) (Figure 2 ).

There was no statistical difference in AOPP levels between patients with positive and negative autologous serum test results ( $3.13 \pm 0.64$ vs. $2.72 \pm 0.96 ; p=0.218$ ) as in AGE ( $434.75 \pm 68.52$ vs. $402.6 \pm 269.87 ; p=0.534)$.

There was no statistical difference in AOPP levels between patients with positive and negative autologous plasma test results ( $3.03 \pm 0.88$ vs. $2.56 \pm 0.84 ; p=0.62$ ) as in AGE (416.2 \pm 246.83 vs. $400.14 \pm 91.3 ; p=0.972)$.

There was a positive correlation between AOPP and AGE levels in patients $(\rho=0.35 ; p=0.001)$ and in controls $(\rho=0.41 ; p=0.001)$. There was a negative correlation between patient's age and duration of urticaria ( $\rho=$ $-0.22 ; p=0.039$ ), but not between stress markers (AOPP and AGE) and duration of urticaria.

\section{Discussion}

Determination of circulating levels of AGEs and AOPPs in oxidative stress is an area of increasing inter-

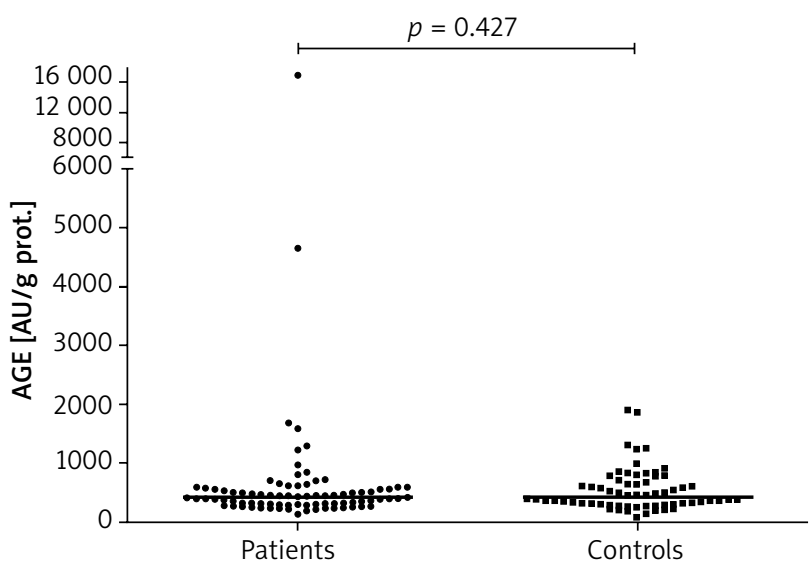

Figure 2. Advanced glycation end (AGE) products concentration in patients and in controls, lines represent means 
est, as is detection of inflammatory markers in several diseases.

The AGEs are composed of a heterogeneous group of bioactive compounds (e.g., pentosidine, carboxymethyl lysine, and imidazolone) that are formed by nonenzymatic glycation of macromolecules [8]. Formation of AGEs is markedly increased in hyperglycaemia but today there is increasing evidence that formation of AGEs has a role also in pathogenesis of several different diseases accompanied by oxidative stress and inflammation, including atherosclerosis, chronic obstructive pulmonary disease, rheumatoid arthritis, and multiple sclerosis [26-32].

The AOPPs are proteins (predominantly albumin and its aggregates) that are damaged by oxidative stress. They contain abundant dityrosines, which enable crosslinking, disulfide bridges, and carbonyl groups and are mainly formed by chlorinated oxidants (hypochlorous acid and chloramines) resulting from myeloperoxidase activity [9]. Apart from a common formation mechanism (oxidative stress) leading to macromolecule damage, the biological effects of AOPPs are similar to those of AGES and are considered to have a role in inflammatory processes and immune dysregulation [33]. Several studies have demonstrated that formation of AGEs and AOPPS may be accelerated in immunological and allergic disorders such as asthma, rhinitis, allergy to hymenoptera venom and mastocytosis [34-40].

In the present study we evaluated serum levels of AOPPS, AGEs in patients affected by chronic urticaria, a disease in which findings on the presence or absence of oxidative stress are controversial [12, 13, 15, 17, 18].

We found higher levels of serum AOPPs in patients than in healthy controls, although the serum levels of AGEs in patients were similar to those of controls. To our knowledge, this is the first study showing the possible involvement of AOPPs in SCU.

Conflicting data have been collected about the oxidative stress status in patients with urticaria.

Some studies suggest the presence of an oxidative insult in physical urticaria [11], acute urticaria [19], chronic idiopathic urticaria $[12,13,18]$ and CSU [17] but other authors did not find significant differences in oxidative stress markers and/or antioxidant capacity between patients with urticaria and controls $[15,16]$ or found that a full oxidative stress does not occur due to well-preserved functions of other scavenger enzymes [18].

However, the sites where oxidative stress markers were detected in chronic idiopathic urticaria and CSU are different: platelet [17], erythrocyte [15, 16, 18], lesional skin [12] and serum [13]. Therefore, the contrasting data may be due to these different methods performed. The works showing the absence of oxidative stress involvement in chronic urticaria detected the markers in erythrocyte $[15,16,18]$ and plasma [17].

In the literature, there is no evidence of AOPPs or AGEs utilization as oxidative stress markers in urticaria.
Our data seem to indicate that AOPPs could be used as an oxidative stress marker since their levels in patients were statistically higher than those in controls confirming the presence of the oxidative status. Instead, AGE levels in patients were not higher than those in controls suggesting their poor output in chronic urticaria.

The different behaviour observed for AOPPs and AGES is probably due to the activation of specific biochemical pathways related to the disease under study.

\section{Conclusions}

These findings confirm that an oxidative status occurs in patients suffering from chronic urticaria, as shown by the occurrence of higher serum levels of AOPPS.

Other studies need to be conducted but AOPPs, and not AGEs, could point the way to a simple, cheap and widespread oxidative stress marker in urticaria.

\section{Conflict of interest}

The authors declare no conflict of interest.

\section{References}

1. Zuberbier T, Aberer W, Asero R, et al. The EAACI/GA(2) LEN/ EDF/WAO Guideline for the definition, classification, diagnosis, and management of urticaria: the 2013 revision and update. Allergy 2014; 69: 868-87.

2. Lang DM. Evidence-based diagnosis and treatment of chronic urticaria/angioedema. Allergy Asthma Proc 2014; 35: 10-6.

3. Weldon D. Quality of life in patients with urticaria and angioedema: assessing burden of disease. Allergy Asthma Proc 2014; 35: 4-9.

4. Hein R. Chronic urticaria: impact of allergic inflammation. Allergy 2002; 57 Suppl 75: 19-24.

5. Kaplan AP, Greaves M. Pathogenesis of chronic urticaria. Clin Exp Allergy 2009; 39: 777-87.

6. Okayama Y. Oxidative stress in allergic and inflammatory skin diseases. Curr Drug Targets Inflamm Allergy 2005; 4: 517-9.

7. Holguin F, Fitzpatrick A. Obesity, asthma, and oxidative stress. J Appl Physiol 2010; 108: 754-9.

8. Kalousová M, Zima T, Tesar V, et al. Advanced glycoxidation end products in chronic diseases-clinical chemistry and genetic background. Mutation Res 2005; 579: 37-46.

9. Piwowar A. Advanced oxidation protein products. Part I. Mechanism of the formation, characteristics and property. Pol Merkuriusz Lek 2010; 28: 166-9.

10. Miraglia N, Assennato G, Clonfero E, et al. Biologically effective dose biomarkers. G Ital Med Lav Ergon 2004; 26 : 298-301.

11. Briganti S, Cristaudo A, D’Argento $V$, et al. Oxidative stress in physical urticarias. Clin Exp Dermatol 2001; 26: 284-8.

12. Raho G, Cassano N, D’Argento V, et al. Overexpression of Mn-superoxide dismutase as a marker of oxidative stress in lesional skin of chronic idiopathic urticaria. Clin Exp Dermatol 2003; 28: 318-20.

13. Cassano N, Raho G, Filieri M, et al. Influence of desloratadine on oxidative stress markers in patients with chronic idiopathic urticaria. Int J Dermatol 2006; 45: 394-6. 
14. Cornejo-Garcia JA, Mayorga C, Torres MJ, et al. Anti-oxidant enzyme activities and expression and oxidative damage in patients with non-immediate reactions to drugs. Clin Exp Immunol 2006; 145: 287-95.

15. Kasperska-Zajac A, Brzoza Z, Polaniak R, et al. Markers of antioxidant defence system and lipid peroxidation in peripheral blood of female patients with chronic idiopathic urticaria. Arch Dermatol Res 2007; 298: 499-503.

16. Kasperska-Zajac A, Brzoza Z, Rogala B, et al. Antioxidant enzyme activity and malondialdehyde concentration in the plasma and erythrocytes of patients with urticarial induced by nonsteroidal anti-inflammatory drugs. J Investig Allergol Clin Immunol 2008; 18: 372-5.

17. Rajappa M, Chandrashekar L, Sundar I, et al. Platelet oxidative stress and systemic inflammation in chronic spontaneous urticaria. Clin Chem Lab Med 2013; 51: 1789-94.

18. Sagdic A, Sener O, Bulucu F, et al. Oxidative stress status in patients with chronic idiopathic urticaria. Allergol Immunopathol 2011; 39: 150-3.

19. Kalkan G, Seçkin HY, Duygu F, et al. Oxidative stress status in patients with acute urticaria. Cutan Ocul Toxicol 2014; 33: 109-14

20. Kaplan AP. Urticaria and angioedema. In: Allergy: Principles and Practice. Middleton E, Reed CE, Ellis EF, et al. (eds). CV Mosby, St Louis 1993; 1562-64.

21. Norman P. Skin testing. In: Manual of Clinical Immunology. Rose NR, Friedman H (eds). American Society of Microbiology, Washington (DC) 1980; 789-93.

22. Vervloet D, Pradal M. In: Kabi Pharmacia. Drug Allergy. Uppsala 1992.

23. Simon RA, Stevenson DD. Adverse reactions to food and drug additives. In: Allergy: Principles and Practice. Middleton E, Reed CE, Ellis EF, et al. (eds). CV Mosby, St Louis, MO 1993; 1687-704.

24. Sabroe RA, Grattan CE, Francis DM, et al. The autologus serum skin test: a screening test for autoantibodies in chronic idiopathic urticaria. Br J Dermatol 1999; 140: 446-52.

25. Kontou-Fili K, Borici-Mazi R, Kapp A, et al. Physical urticaria: classification and diagnostic guidelines. Allergy 1997; 52 504-13.

26. Spatari G, Saitta S, Cimino F, et al. Increased serum levels of advanced oxidation protein products and glycation end products in subjects exposed to low-dose benzene. Int J Hyg Environ Health 2012; 15: 389-92.

27. Lin CH, Kadakia S, Frieri M. New insights into an autoimmune mechanism, pharmacological treatment and relationship between multiple sclerosis and inflammatory bowel disease. Autoimmun Rev 2014; 13: 114-6.

28. Gangemi S, Allegra A, Aguennouz M, et al. Relationship between advanced oxidation protein products, advanced glycation end products, and S-nitrosylated proteins with biological risk and MDR-1 polymorphisms in patients affected by B-chronic lymphocytic leukemia. Cancer Invest 2012; 30: 20-6.

29. de Groot L, Hinkema H, Westra J, et al. Advanced glycation endproducts are increased in rheumatoid arthritis patients with controlled disease. Arthritis Res Ther 2011; 13: R205.

30. Sternberg Z, Ostrow P, Vaughan M, et al. AGE-RAGE in multiple sclerosis brain. Immunol Invest 2011; 40: 197-205.

31. Wu L, Ma L, Nicholson LF, et al. Advanced glycation end products and its receptor (RAGE) are increased in patients with COPD. Respir Med 2010; 105: 329-36.

32. Gangemi S, Allegra A, Sciarrone P, et al. Effect of therapeutic plasma exchange on plasma levels of oxidative biomarkers in a patient with thrombotic thrombocytopenic purpura. Eur J Haematol 2015; 94: 368-73.

33. Tsukahara $\mathrm{H}$, Shibata R, Ohta N, et al. High levels of urinary pentosidine, an advanced glycation end product, in children with acute exacerbation of atopic dermatitis: relationship with oxidative stress. Metabolism 2003; 52: 1601-5.

34. Sathiyapriya V, Bobby Z, Vinod Kumar S, et al. Evidence for the role of lipid peroxides on glycation of hemoglobin and plasma proteins in non-diabetic asthma patients. Clin Chim Acta 2006; 366: 299-303

35. Tochino $Y$, Kanazawa H, Ichimaru $Y$, et al. Nepsilon(carboxymethyl)lysine, a major advanced glycation end product in exhaled breath condensate as a biomarker of small airway involvement in asthma. J Asthma 2007; 44: 861-6.

36. Aksoy F, Demirhan H, Veyseller B, et al. Advanced oxidation protein products as an oxidative stress marker in allergic rhinitis. Kulak Burun Bogaz Ihtis Der 2009; 19: 279-84.

37. Kanazawa H, Tochino Y, Kyoh S, et al. Potential roles of pentosidine in age-related and disease related impairment of pulmonary functions in patients with asthma. J Allergy Clin Immunol 2011; 127: 899-904.

38. Di Lorenzo G, Minciullo PL, Leto-Barone MS, et al. Differences in the behavior of advanced glycationed products and advanced oxidation protein products in patients with allergic rhinitis. J Investig Allergol Clin Immunol 2013; 23: 101-6.

39. Patella V, Incorvaia C, Minciullo PL, et al. Oxidative stress markers in patients with hymenoptera venom allergy. Allergy Asthma Proc 2015; 36: 9-13.

40. Gangemi S, Minciullo PL, Magliacane D, et al. Oxidative stress markers are increased in patients with mastocytosis. Allergy 2015; 70: 436-42. 